Supplement of

\title{
Signatures of human intervention - or not? Downstream intensification of hydrological drought along a large Central Asian river: the individual roles of climate variability and land use change
}

Artemis Roodari et al.

Correspondence to: Artemis Roodari (artemis_roodari@yahoo.com)

The copyright of individual parts of the supplement might differ from the article licence. 
Table S1. Water balance and constitutive equations used in FLEX model

\begin{tabular}{|c|c|c|c|c|}
\hline Reservoirs & Water balance equations & & Constructive equations & \\
\hline Snow & $\frac{d S_{s n}}{d t}=P_{s}-M$ & (1) & $\begin{aligned} P_{s} & = \begin{cases}P ; & T<T_{t} \\
0 ; & T \geq T_{t}\end{cases} \\
M & = \begin{cases}0, & T<T_{t} \\
\min \left(F_{d d}\left(T-T_{t}\right), \frac{s_{s n}}{d t}\right), & T \geq T_{t}\end{cases} \end{aligned}$ & $\begin{array}{l}(2) \\
(3)\end{array}$ \\
\hline Interception & $\frac{d s_{i}}{d t}=P_{r}+M-P_{e}-E_{i}$ & (4) & $\begin{array}{c}P_{r}= \begin{cases}0 ; & T<T_{t} \\
P ; & T \geq T_{t}\end{cases} \\
P_{e}=\max \left(0, \frac{S_{i}-I_{\max }}{d t}\right) \\
E_{i}=\min \left(E_{P}, \frac{S_{i}-P_{e}}{d t}\right)\end{array}$ & $\begin{array}{l}\text { (5) } \\
(6) \\
(7)\end{array}$ \\
\hline Unsaturated reservoir & $\frac{d S_{u}}{d t}=P_{e}\left(1-C_{r}\right)-R_{s}-E_{T}$ & (8) & $\begin{array}{l}C r=1-\left(1-\frac{s_{u}}{s_{u, \max }(1+\beta)}\right)^{\beta} \\
R_{s}=\min \left(P_{\max }\left(\frac{s_{u}}{s_{u, \max }}\right), \frac{s_{u}}{d t}\right) \\
E_{T}=\min \left(\left(E_{0}-E_{i}\right) \min \left(\frac{s_{u}}{s_{u, \max } C_{e}}, 1\right), \frac{s_{u}}{d t}\right) \\
R_{f}=P_{e} C_{r}\end{array}$ & $\begin{array}{r}(9) \\
(10) \\
(11) \\
(12)\end{array}$ \\
\hline Fast reservoir & $\frac{d S_{f}}{d t}=R_{f}-Q_{f}$ & (13) & $Q_{f}=S_{f} K_{f}$ & (14) \\
\hline Slow reservoir & $\frac{d S_{s}}{d t}=R_{s}-Q_{s}$ & $(15)$ & $\begin{array}{l}Q_{s}=S_{s} K_{s} \\
Q=\left(1-K_{L}\right)\left(Q_{f}+Q_{s}\right)\end{array}$ & $\begin{array}{l}(16) \\
(17)\end{array}$ \\
\hline
\end{tabular}



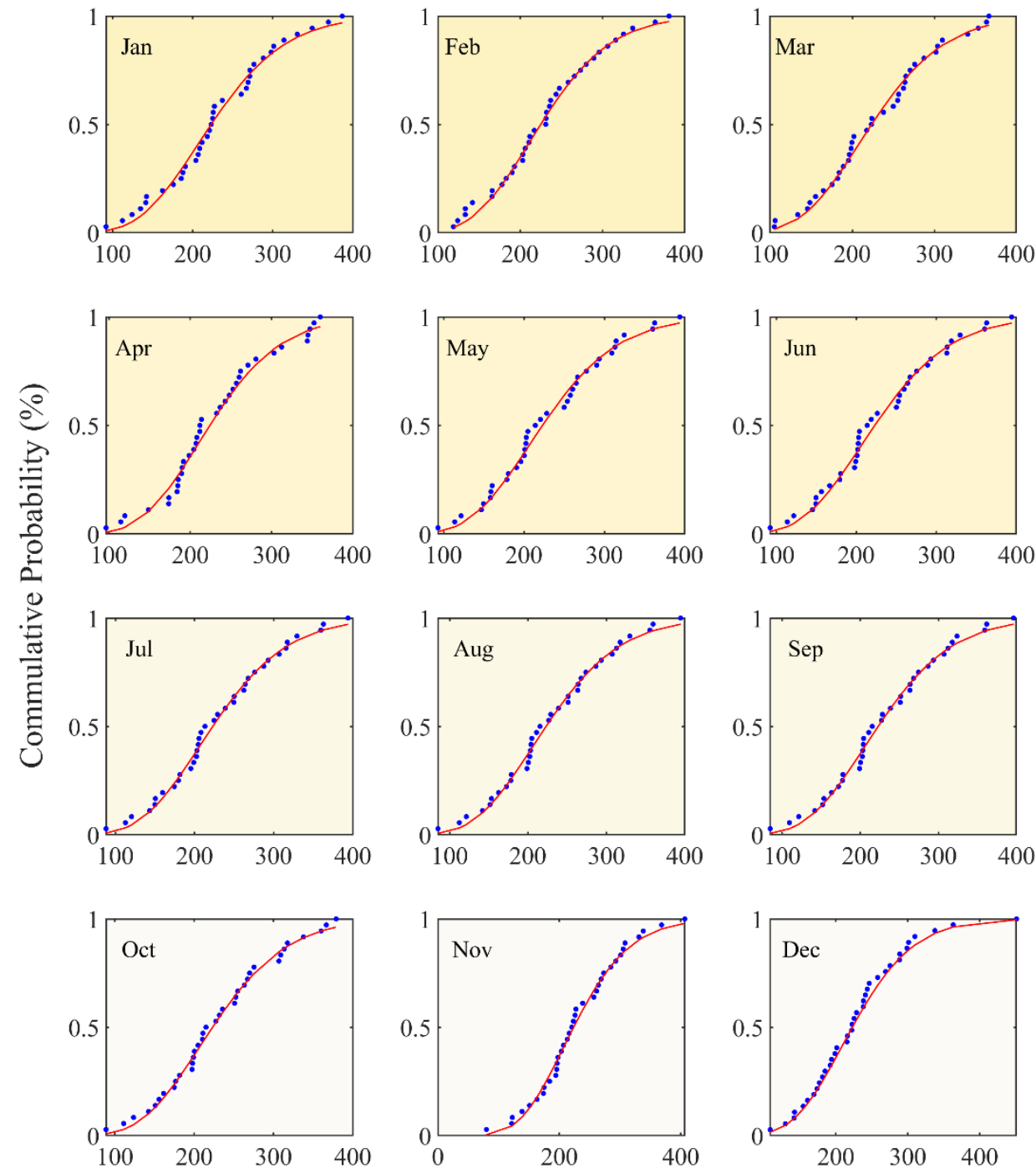

Precipitation $\left(\mathrm{mmyr}^{-1}\right)$

Figure S1. Cumulative gamma distribution function (CDF) of 12-month aggregated precipitation to estimate SPI in each month in the HRB. The red line and blue dots indicate the fitted and empirical gamma CDF, respectively. 

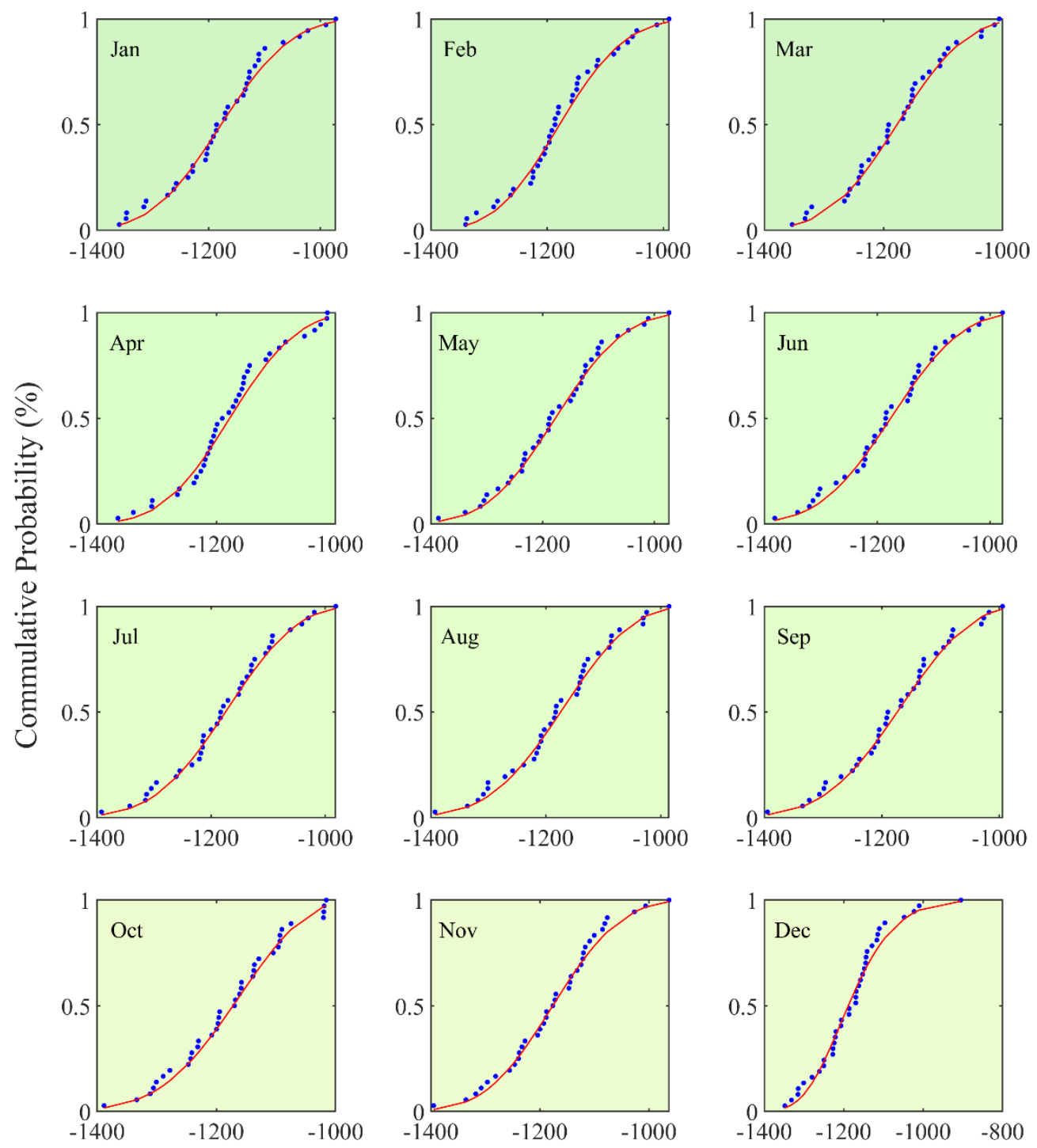

Precipitation-Evapotranspiration $\left(\mathrm{mmyr}^{-1}\right)$

Figure S2. Generalized extreme value (GEV) cumulative distribution of moisture deficit (Precipitation-Evapotranspiration) to estimate SPEI in each month in the HRB. The red line and blue dots indicate the fitted and empirical GEV, respectively. 

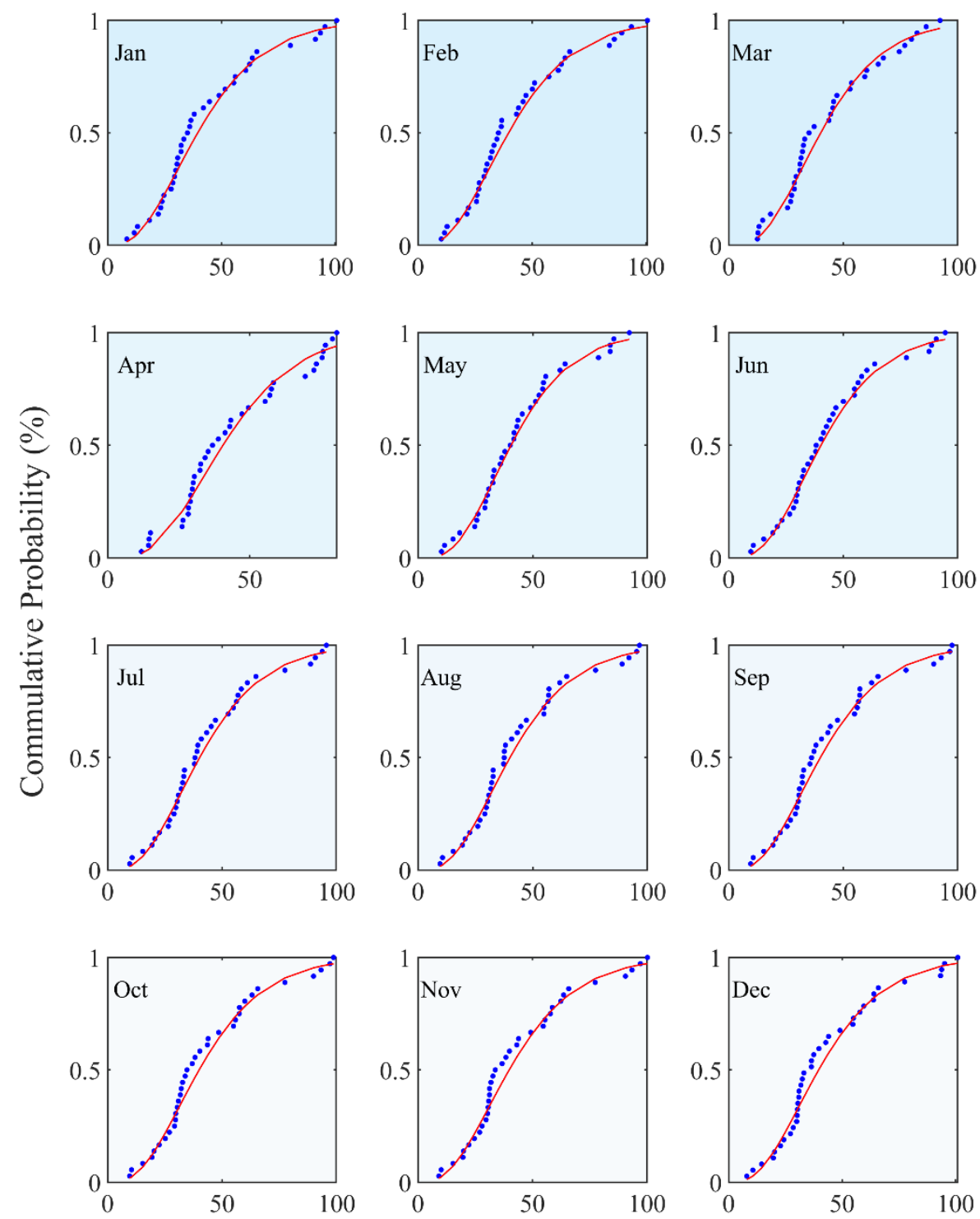

Streamflow $\left(\mathrm{mmyr}^{-1}\right)$

Figure S3. Cumulative gamma distribution function (CDF) of 12-month aggregated streamflow to estimate SDI in each month in the HRB. The red line and blue dots indicate the fitted and empirical gamma CDF, respectively. 


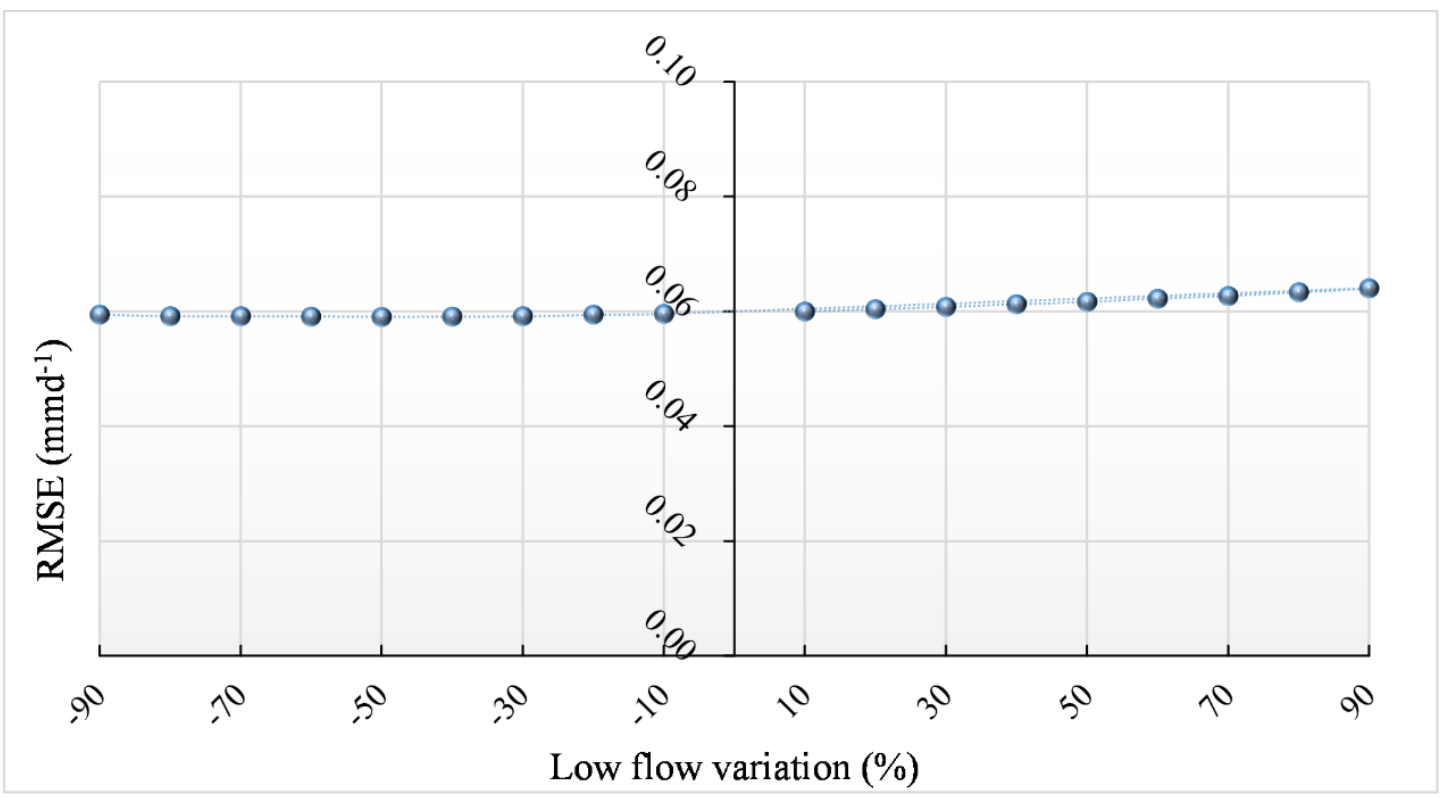

Figure S4. Sensitivity analysis of the effects of uncertainties in the low flow reservoir routing scheme on downstream flow of HRB. The blue dots show the average root mean square error (RMSE) of reproduced flow downstream of Kajakai dam by using various percentiles of the confidence interval of the reservoir low flow storage-discharge equation. 

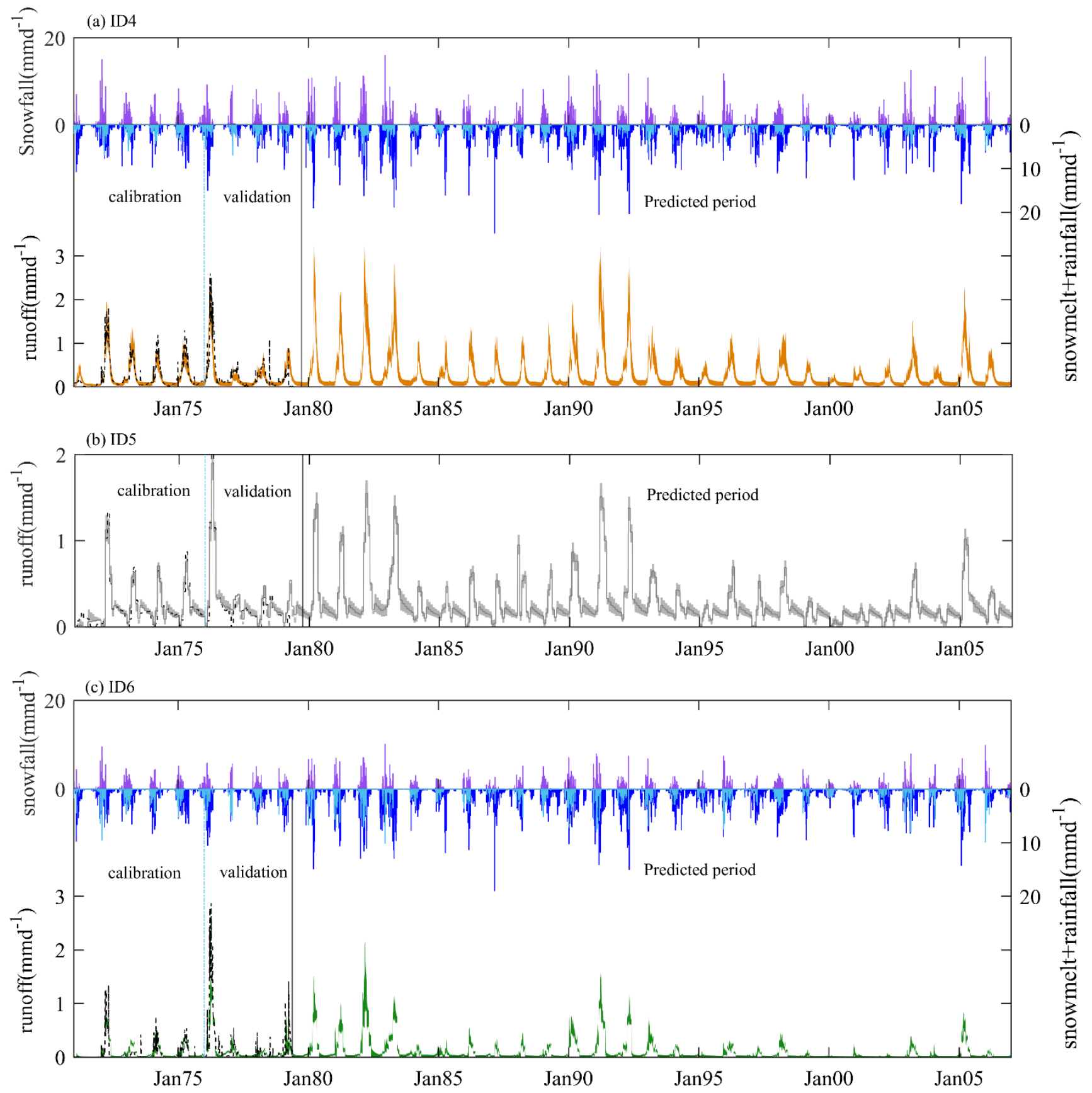

Figure S5. Precipitation and streamflow in $\mathrm{UARB}_{U}\left(\right.$ ID4), UARB ${ }_{\mathrm{D}}$ (ID5) and LARB (ID6). The purple bars show the modelled snowfall $\mathrm{P}_{\mathrm{S}}\left[\mathrm{mm} \mathrm{d}^{-1}\right]$, the dark blue bars the modelled snowmelt $\mathrm{M}\left[\mathrm{mm} \mathrm{d}^{-1}\right]$ and the light blue bars the modelled rainfall $\mathrm{P}_{\mathrm{R}}[\mathrm{mm}$ $\mathrm{d}^{-1}$. The dashed black lines indicate the observed runoff and the shaded areas the uncertainty ranges of modelled runoff during calibration, validation and prediction periods. 

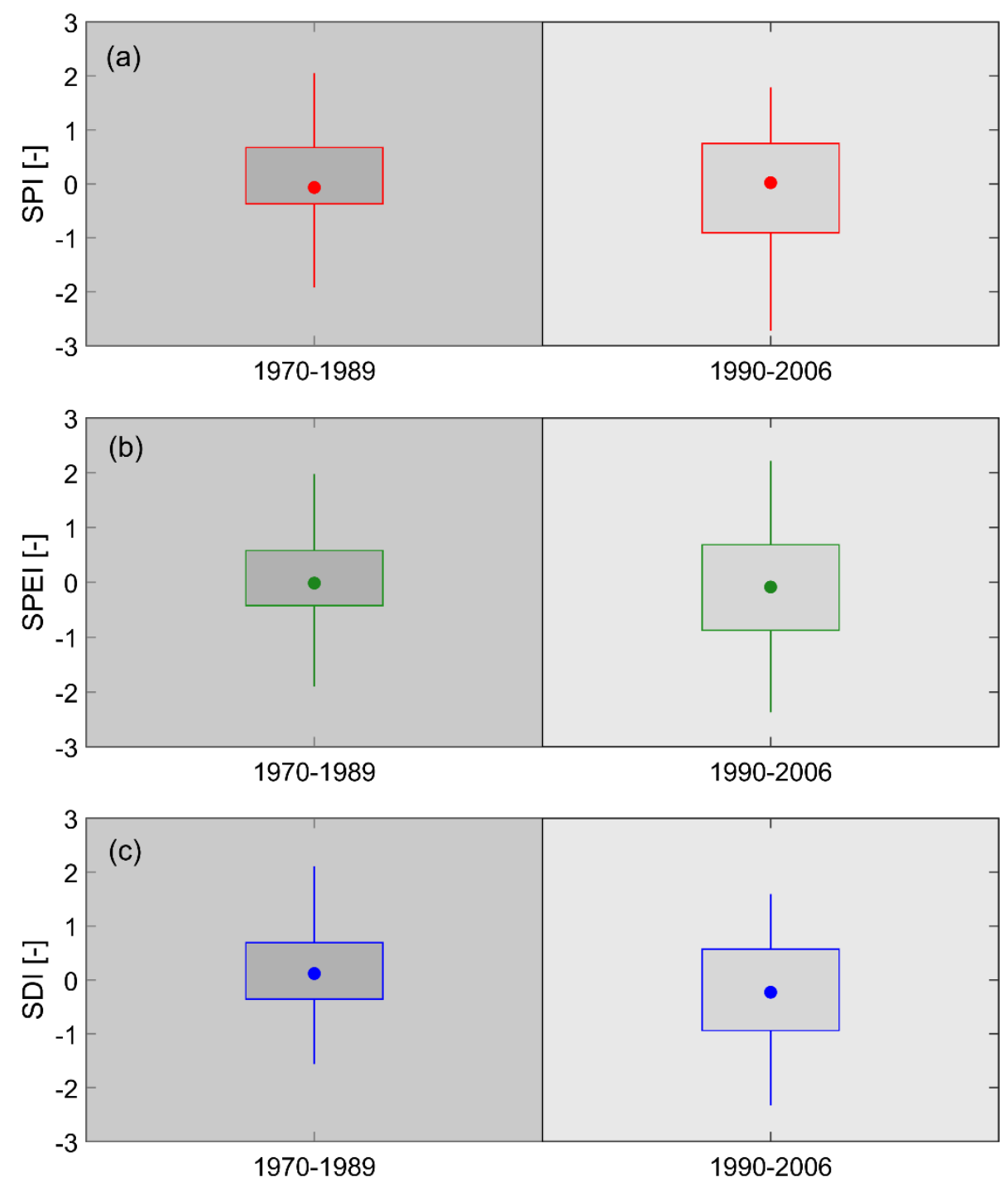

Figure S6. Distributions of the mean basin (a) SPI, (b) SPEI and (c) SDI over the study period. The dots in the box plots indicate the median values and the whiskers the 5/95th percentiles. 